\title{
Letrônica
}

\section{A visão enciclopédica dos frames semânticos}

The encyclopedic vision of semantic frames

Doutora em Linguística Aplicada pela PUCRS em Linguística Aplicada e do curso de Letras da Universidade do Vale do Rio dos Sinos, Sâo Leopoldo, RS, Brasil. Bolsista de Produtividade em Pesquisa do CNPq. 003-2287-5548 E-mail: rove@unisinos br

Recebido em: 10/5/2019 Aprovado em. 10/201/2019

\section{Endereço para correspondência:} Curso de Letras

Universidade do Vale do Rio dos Sinos Av. Unisinos, 950 - Cristo R

190, São Lenoldo RS, Brasil
Rove Chishman 1

\author{
Universidade do Vale do Rio dos Sinos, Programa de Pós-Graduação em Linguística Aplicada, São Leopoldo, RS, Brasil.
}

\section{RESUMO}

Este trabalho tem como objetivo discorrer sobre a natureza enciclopédica dos frames semânticos e o seu papel na prática lexicográfica. Em termos teóricos, procuramos compreender a visão de Charles Fillmore $(1982,1992)$ com a proposição da Semântica de Frames, assim como buscar na Linguística Cognitiva os seus princípios. Em termos aplicados, focalizamos na interface da Semântica de Frames com a Lexicografia e apresentamos, na sequência, dois estudos de caso, ambos destacando a visão enciclopédica dos frames e a sua pertinência para a prática lexicográfica. Destacamos, por fim, tratar-se da ocupação de um nicho específico de pesquisa, à medida que nos voltamos apenas para os frames semânticos. Ressalta-se que outros tópicos da Semântica Cognitiva também têm a sua relevância para a Lexicografia.

Palavras-chave: Frames. Lexicografia Eletrônica. Semântica.

\section{ABSTRACT}

This study aims at discussing the encyclopedic nature of semantic frames and their role in lexicographic practice. In theoretical terms, we try to understand the vision of Charles Fillmore $(1982,1992)$ with the proposition of Frames Semantics, as well as to seek in Cognitive Linguistics its principles. In applied terms, we focused on the interface between Frames Semantic and Lexicography and presented, in the sequence, two case studies, both highlighting the encyclopedic vision of the frames and their relevance to the lexicographic practice. We emphasize, finally, the occupation of a specific niche of research, as we return only to the semantic frames. It is noteworthy that other topics of Cognitive Semantics also have their relevance for lexicography.

Keywords: Frames. Electronic Lexicography. Semantics. 


\section{Introdução}

Pro ste ste trabalho tem como objetivo discorrer sobre a natureza enciclopédica dos frames semânticos e o seu papel na prática lexicográfica. Em termos teóricos, importa apresentar a visão de Charles Fillmore, que, nos meados dos anos de 1980, já apresentava a sua visão de frames como sistemas de conceitos relacionados de tal forma que, para compreender o significado de um deles, é necessário compreender a estrutura como um todo. É com esse propósito, que também resgatamos alguns princípios basilares da Linguística Cognitiva, quadro teórico mais amplo a que a teoria fillmoriana se vincula, para melhor compreender a visão de que o significado é enciclopédico, perspectivista, flexível e baseado na experiência e no uso.

Em termos aplicados, interessa-nos focar na aproximação entre a Semântica de Frames e a Lexicografia. Ainda que estudos que evidenciem a pertinência da teoria fillmoreana como aporte teórico para a estruturação de obras lexicográficas sejam recentes, e ainda pouco explorados, a discussão sobre o emprego de teorias semânticas como norteadoras na construção de recursos lexicográficos é antiga e, em algum sentido, longe de ser consensual. É tendo em vista tal cenário que organizamos a segunda parte deste trabalho, a qual se ocupa inicialmente de tal discussão para, em um segundo momento, apresentar dois estudos realizados no âmbito das pesquisas do grupo de pesquisa SemanTec ${ }^{1}$, que ilustram a aplicabilidade dos frames semânticos, em especial, o seu caráter enciclopédico.

As pesquisas desenvolvidas pelo grupo SemanTec, ao longo dos últimos dez anos, têm se ocupado em investigar a pertinência da noção de frame como princípio organizador de recursos lexicográficos digitais.

${ }^{1}$ Grupo de pesquisa criado em 2000 e credenciado no CNPq. Vinculado à UNISINOS, o Grupo Semântica e que oferece a aproximação entre a Linguística, em especial a Semântica, e a Informática.
Distinguem-se do projeto pioneiro de Fillmore, a base de dados FrameNet, à medida que passam a considerar requisitos especificamente lexicográficos, e não apenas linguístico-computacionais.

Nesse período, o grupo lançou o Field: dicionário de expressões do futebol $^{2}$ (CHISHMAN, 2014) e o Dicionário Olímpico ${ }^{3}$ (CHISHMAN et al., 2016). Seguindo essa mesma esteira, estão outros dois recursos - o Portal Lexicográfico Jurídico e o Dicionário Paraolímpico - ambos em desenvolvimento. As exemplificações apresentadas na sequência situam-se nesse contexto de pesquisa.

\section{Os princípios da Linguística Cognitiva}

No intuito de compreender tal visão de significado, é importante, antes que se resgatem os princípios da Linguística Cognitiva, que se faça referência ao próprio estatuto da Semântica no âmbito da História da Linguística do século XX, assim como no âmbito da Filosofia da Linguagem. Geeraerts (2003) destaca que a linguística desse período se caracterizou por uma sucessão de movimentos autonomistas descontextualizadores e de movimentos recontextualizadores. As dicotomias língua/fala (Saussure) e competência/ desempenho (Chomsky) viriam criar uma concepção de linguagem com uma lacuna no meio. Ainda que não se tenha um espelhamento entre os dois pares, haja vista que a langue saussureana é definida como um sistema social, um conjunto de convenções coletivas, um código compartilhado por uma comunidade e, a competência, como gramática internalizada, ambas as visões excluíram os aspectos variáveis, contextuais e culturais da linguagem, o que as caracterizaria como descontextualizadoras. Segundo Geeraerts (2003), Chomsky, ao invés de propor uma visão tricotômica, ternária,

2 Disponível em: www.dicionariofield.com.br. Acesso em: 2 mar. 2019

3 Disponível em: www.dicionarioolimpico.com.br. Acesso em: 23 abr. 2019. 
restringe a sua concepção de linguagem a uma nova dicotomia, à medida que prioriza a perspectiva genética e ignora os aspectos culturais e sociais.

Concebendo a linguagem natural como uma entidade genética e autônoma, o Gerativismo reserva para a semântica um papel secundário, haja vista que significados constituem os aspectos variáveis e contextuais por excelência. E foi como uma reação ao lugar periférico ocupado pelo componente semântico nos diferentes modelos da teoria gerativa (a iniciar pela Teoria Padrão), que surgiu, no final dos anos de 1960 e início dos anos de 1970, o movimento conhecido como Semântica Gerativa, comandado por Lakoff, Ross, Postal e McCawley, o qual, em embate com a Semântica Interpretativa (JACKENDOFF, 1972), veio motivar o surgimento da Linguística Cognitiva.

Com viés marcadamente recontextualizador, nos termos de Geeraerts (2003), a Linguística Cognitiva surge rejeitando a visão dualista cartesiana, assim como o princípio da modularidade da mente e a autonomia da sintaxe. Soares (2006) esclarece que, por decorrência de tal contraste de posicionamentos, passa a existir uma oposição maior entre as teorias referenciais e as teorias conceptuais do significado, ou seja, entre a concepção do significado como algo analisável em termos de condições-deverdade através da lógica formal e de uma concepção de significado como uma entidade mental e conectada com a experiência humana.

Chishman e Santos (2017, p. 53-71) se debruçam sobre o contraste dessas duas visões e procuram situar os estudos de orientação sociocognitivista na discussão acerca da referência. Apoiadas em Lakoff e Johnson (1999), que em Philosophy in the Flesh defendem que a Filosofia deve partir de uma ciência empiricamente responsável, o que, em outros termos, implica avaliar a adequação empírica dos argumentos filosóficos sobre conceitos, mente e linguagem, as autoras ressaltam que é possível, com a visão experiencialista, assumir uma posição intermediária no que concerne ao processo de referência e considerar a existência de um objetivismo a partir de uma noção diferente de realidade objetiva, esta calcada em um sistema conceptual condicionado a uma cultura, segundo o qual existem verdades corroboradas pelos membros da comunidade.

É nesse sentido que se torna importante situar a Linguística Cognitiva como vinculada ao que Lakoff e Johnson (1999, apud CHISHMAN; SANTOS, 2017) denominam de Realismo Corporificado ou Realismo Experiencialista, "concepção que parte da rejeição de dicotomias como racionalismoempirismo e sujeito-objeto e confia no fato de que nós lidamos com o mundo através de nossas interações corporificadas", em contraste com o Objetivismo. Como decorrência da visão experiencialista, concebe-se o pensamento como corporificado, imagético, gestáltico e centrado na estrutura conceptual.

Referindo-se especificamente à Semântica Cognitiva, subárea da Linguística Cognitiva que investiga as relações entre a experiência, o sistema conceptual e a estrutura semântica expressa pela linguagem, Evans e Green (2006, p. 157) apontam como centrais os seguintes compromissos:

(i) A estrutura conceptual é corporificada;

(ii) A estrutura semântica é a estrutura conceptual;

(iii) A representação do significado é enciclopédica;

(iv) A construção do significado é conceptualização.

Sobre o compromisso com a conceptualização, Langacker (1987, p. 154-166) destaca que, se o significado é conceptualização, então tudo tem a ver com a experiência humana. Acrescenta que, "conceptualizamos e verbalizamos através de mentes corporificadas (embodied) e em constante interação com o mundo e com os outros". Em outras palavras, assim como não existe cognição fora do contexto, não existe linguagem humana independentemente da interação e do contexto sociocultural.

No que diz respeito ao compromisso com a perspectiva enciclopédica, o autor, referindo-se à compreensão do significado linguístico, acrescenta que a visão experiencialista nos leva a assumir uma semântica enciclopédica, o 
que implica dizer que "uma expressão só é significativa na medida em que evocar um conjunto de conhecimentos - os chamados "domínios cognitivos" (LANGACKER, 1987), "modelos cognitivos idealizados" (LAKOFF, 1987), "espaços mentais" (FAUCONNIER, 1985) ou frames (FILLMORE, 1977)".

Sobre a assunção de que o significado é enciclopédico, os semanticistas cognitivos se apoiam em duas justificativas: a primeira diz respeito ao fato de que a estrutura semântica dá acesso a um vasto inventário de conhecimento estruturado, o que corresponde ao compromisso com a conceptualização, e a segunda refere-se à experiência social, relação e interação entre os seres humanos, assim como na própria experiência corpórea (SPADER, 2019).

Por fim, importa fazer menção à distinção entre o componente dicionarístico e o componente enciclopédico estabelecida pelos linguistas formais da década de 1960. Em outras palavras, pode-se falar em distinção entre o dicionário e a enciclopédia ou, grosso modo, entre o conhecimento linguístico e o conhecimento extralinguístico. Para os formalistas, apenas o componente de dicionário poderia ser investigado por uma teoria linguística, já que, sob tal ótica, o conhecimento enciclopédico é externo ao linguístico.

De acordo com a visão aqui defendida, ainda que se admita, conforme Evans e Green destacam, que o componente dicionarístico está relacionado ao significado das palavras e o componente enciclopédico ao conhecimento de mundo, a constituição do significado decorre tanto do componente dicionarístico como do componente enciclopédico. Com isso, não apenas a dicotomia dicionário/enciclopédia é abrandada, como a clássica distinção entre semântica e pragmática.

\section{A natureza enciclopédica dos frames semânticos}

Para compreender a noção de frame, em especial seu compromisso com a visão enciclopédica, é importante registrar que a teoria fillmoreana passou por diferentes momentos e reformulações, e os seus pilares se estabeleceram bem antes de a Linguística Cognitiva se firmar como empreendimento em torno do qual se agrupam as teorias que compartilham as mesmas concepções de linguagem e de cognição.

Ainda que a história da Semântica de Frames tenha como marco oficial os anos de 1970, cabe pontuar que Fillmore foi um dos expoentes da teoria da gramática gerativa em sua fase inicial e foi nesse período que ele desenvolveu a teoria da Gramática de Casos (FILLMORE, 1968). Nessa primeira fase, seus trabalhos focalizavam a sintaxe, a classificação dos verbos em inglês, os papéis semânticos e a noção de valência.

Foi a partir de seus estudos acerca dos "casos" que Fillmore avançou na proposição de papéis semânticos como categorias a ser aplicadas em várias línguas e como importantes para determinar a gramaticalidade das sentenças, como em "João quebrou a janela" e "O martelo quebrou a janela", em que se têm, na posição de sujeito, agente e instrumento como papéis semânticos (FILLMORE, 1975).

Os anos 1970 trouxeram refinamentos importantes para a concepção de frame. Foi nesse período que Fillmore defendeu a crucialidade do conceito de protótipo, tal como proposto por Eleanor Rosch $(1973 ; 1975)$, e definiu frame como "qualquer sistema de escolhas linguísticas - os casos mais fáceis sendo coleções de palavras, mas também incluindo escolhas de regras gramaticais ou categorias linguísticas - que podem estar associadas a instâncias prototípicas de cenas" (FILLMORE, 1975, p. 124, tradução nossa) ${ }^{4}$. Ao se valer da noção de protótipo, Fillmore passou a considerar que, para a ativação dessas cenas a partir de um frame linguístico, dispõe-se de um repertório mental de protótipos. Em outras

${ }^{4}$ Do original: [...] any system of linguistic choices - the easiest cases being collections of words, but also including choices of grammatical rules or linguistic categories - that can get associated with prototypical instances of scenes. 
palavras, implica assumir a tese de que frames são instâncias prototípicas da experiência humana.

É também nesse período que Fillmore estabeleceu como importante a distinção entre frame e cena, sendo que frame estaria associado ao nível linguístico, e a cena, ao nível conceptual. Sob tal ótica, o frame caracterizaria as palavras e expressões que servem de pontos de acesso para o conteúdo semântico ou conceptual. Enfatiza-se, portanto, que a noção de frame, nessa fase inicial da teoria, ainda estava muito atrelada à língua.

Foram, sem dúvida, as formulações apresentadas nos textos dos anos 1980 que vieram consolidar a Semântica de Frames:

A Semântica de Frames oferece um modo particular de se olhar para o significado das palavras, e também um modo de caracterizar princípios para criar novas palavras e frases, para adicionar novos sentidos às palavras, e para juntar os sentidos de elementos textuais ao sentido total do texto. Pelo termo frame tenho em mente qualquer sistema de conceitos relacionados de tal maneira que para entender qualquer um deles é preciso entender a estrutura que os comporta como um todo; quando um dos itens de tal estrutura é introduzido em um texto ou em uma conversa, todos os outros se tornam automaticamente disponíveis (FILLMORE, 1982, p. 11, tradução nossa) ${ }^{5}$.

Dessa forma, Fillmore passou a assumir que uma palavra estaria sempre atrelada a um contexto maior - o frame - de modo que, para compreendêla, seria necessário levar em conta todos esses elementos subjacentes ao conceito. Não se trata mais do frame linguístico, mas do conceito integrado de framing, que engloba não apenas o frame linguístico, mas também as

\footnotetext{
${ }^{5}$ Do original: Frame semantics offers a particular way of looking at word meanings, as well as a way of characterizing principles for creating new words and phrases, for adding new meanings to words, and I have in mind any system of have in them you
} introduced into a text, or into a conversation, all of the others are automatically made available. cenas. Observa-se, portanto, que tal visão passa a reforçar a faceta cognitiva do frame, assim como uma maior valorização do componente enciclopédico.

A Semântica de Frames passa a propor estudos que revelem as categorias de experiência subjacentes aos usos linguísticos, de modo que os frames constituam o caminho para se entender a razão pela qual determinada comunidade cria certas categorias de palavras, buscando-se explicar o significado através do esclarecimento dessas motivações (FILLMORE, 1982; 1985). Conforme o autor, essas categorias de experiência, bem como outras informações contextuais e culturais, indexam estruturas conceptuais e enfatizam "as continuidades [...] entre linguagem e experiência" (FILLMORE, 1982, p.111, tradução nossa) ${ }^{6}$. Essa valorização do conhecimento enciclopédico pela Semântica de Frames, propõe Fillmore, permite explicar por que determinados usos linguísticos podem ser alterados em virtude de uma percepção dos falantes quanto à necessidade de reframing, ou seja, de uma mudança semântica que reformula as circunstâncias motivacionais subjacentes a determinado uso (FILLMORE, 1982).

Um frame passa a ser descrito como uma esquematização da experiência depositada em nossa memória de longo prazo, elencando os elementos participantes de uma determinada experiência. As palavras, para Fillmore, são "categorizações de experiência", sustentadas por uma situação motivacional que ocorre em um plano de fundo de conhecimento decorrente da forma como nos posicionamos e percebemos o mundo ao nosso redor. Desse modo, os frames podem caracterizar um modo para se entender a razão pela qual determinada comunidade cria certas categorias de palavras, buscando explicar o significado de cada unidade lexical através do esclarecimento de tal motivação. Os frames, nesse sentido, estão intrinsecamente relacionados à cultura.

${ }^{6}$ Do original: [...] the continuities [...] between language and experience. 
Tal relação existente entre o frame semântico de Fillmore e a cultura de cada um pode ser representada a partir de um frame de café da manhã (FILLMORE, 1982). Segundo o linguista,

Entender essa palavra é entender a prática em nossa cultura de ter três refeições diárias, em horários mais ou menos convencionalmente estabelecidos do dia, e sendo que uma dessas refeições é aquela a ser feita no início do dia, após um período de sono, consistindo de um menu um tanto quanto único (cujos detalhes podem variar de comunidade para comunidade) (FILLMORE, 1982, p. 118, tradução nossa) ${ }^{7}$.

De início, temos o fato de que um frame de café da manhã carrega mais do que apenas informações referentes ao que se consome. Compreender o café da manhã significa compreender o papel dessa refeição na nossa sociedade. Podemos ir mais fundo: um café da manhã tradicionalmente americano contém ovos mexidos, bacon, panquecas. É possível que a ausência de algum desses elementos cause estranhamento em uma pessoa acostumada a essa realidade. No entanto, no Brasil, é igualmente possível que a presença dos mesmos elementos cause tal estranhamento. É importante ressaltar que o frame é o mesmo, uma vez que ele está ainda retratando a primeira refeição do dia, feita no início da manhã, após um período de sono, dentre outros aspectos que o caracterizam.

Por fim, ainda recorrendo aos escritos de Fillmore (1982, p. 373, tradução nossa) ${ }^{8}$, deparamo-nos com afirmativas que nos ajudam a compreender em que medida abordagens interacionais e discursivas têm se valido da noção de frame em suas análises:

\footnotetext{
No original: To understand this word is to understand the practice in our culture of having three meals a day, at more or less conventionally established times of the day, and for one of these meals to be the one which is eaten early in the day, after a period of sleep, and for it to consist of a somewhat unique menu (the details of which can vary from community to community).

8 Do original: I intend the word 'frame' as used here to be a general cover term for the set of concepts variously known, in the literature on natural language understanding, as 'schema', 'script', 'scenario', 'ideational scaffolding', 'cognitive model', or 'folk theory'.
}

Frame é um termo geral que diz respeito a todo um conjunto de conceitos conhecidos na literatura como esquema, script, cenário, evento, andaime ideacional, modelo cognitivo ou teoria folk. Cultural e experiencialmente adquiridas e moduladas, tais cenas ou enquadres sociocognitivos atuam na maneira como compreendemos e atuamos no mundo.

Um desses trabalhos que merece destaque é o de Ziem (2014), que parte do conceito de frame como um ato cognitivo de referenciação. Para o autor, "Uma expressão se refere a uma unidade cognitiva ao evocar um frame, o qual então abre uma área de referência potencial” (ZIEM, 2014, p. 251) ${ }^{9}$. 0 processo de referência passa a ser compreendido, considerando a ativação de estruturas conceptuais relativamente estáveis, as quais são partilhadas por uma comunidade de falantes, cuja atividade mental e comunicativa deve ser valorizada (SALOMÃO, 2003).

Perspectiva similar é adotada por Cienki (2007, p. 173), para quem frames configuram-se em termos de esquemas de conhecimento que guiam e estruturam o uso da linguagem, enquadram ou emolduram nossas experiências psicossociais; sendo, portanto, projetivos, generalizantes e convencionais.

Croft e Cruse (2004), por sua vez, destacam a dinamicidade dos frames, haja vista que a dinâmica poder ser identificada nas unidades lexicais, nas expressões referenciais, nas construções predicativas, nas tematizações de experiências, nas manipulações enunciativas de processos meta e de processos figurativos, na relação entre variáveis do contexto interacional situacional e social, nas características da estruturação da conversação e nas formas de categorização social realizadas pelos interagentes.

Do original: A linguistic expression refers to a cognitive unit by evoking a frame, which then opens a potential reference area. 


\section{Aproximações entre Semântica de Frames e Lexicografia}

As aproximações entre Semântica de Frames e Lexicografia começam a ser pauta nos estudos de Fillmore quando, em 1992, em coautoria com Sue Atkins, escreve o artigo "Toward a Frame-based Lexicon: The semantics of RISK and its Neighbors". Tomando como base a análise da unidade lexical risk, Fillmore e Atkins apresentam justificativas para a construção de um dicionário baseado em frames. Silva (2017), em sua tese sobre a pertinência da noção de frame para a Lexicografia Eletrônica, chama a atenção para as indicações apontadas pelos autores nesse artigo de 1992 para a adoção da Semântica de Frames como modelo teórico para o fazer lexicográfico. Dentre as motivações, Fillmore e Atkins (1992, apud SILVA, 2017) destacam que:

O dicionário deve ser, em princípio, capaz de permitir que seus usuários tenham acesso a toda a informação que os falantes possuem sobre as palavras em sua língua; ou seja, não será limitado pelas preocupações usuais de espaço e mercado que restringem a tomada de decisão na produção de dicionários comerciais tradicionais ${ }^{10}$ (FILLMORE; ATKINS, 1992, p. 76, tradução nossa).

Silva (2017), referindo-se à passagem supracitada, chama a atenção não apenas para as limitações de espaço dos dicionários impressos, como também para o modelo online/eletrônico como o mais adequado para expressar as informações previstas pela Semântica de Frames. Outro ponto indicado pelos autores diz respeito à importância em disponibilizar conhecimento enciclopédico. Segundo os autores (1992 apud SILVA, 2017), uma descrição baseada em frames inclui muito mais conhecimento acerca

${ }^{10}$ Do original: The dictionary must be, in principle, capable of allowing its users access to all the information that speakers possess about the words in their language; that is, it will not be limited by the usual space and marketability concerns that constrain decision making in the production of traditional commercial dictionaries. da totalidade de informações relacionadas a um item do léxico, o que viria a contribuir para que os usuários de um dicionário sejam capazes de compreender melhor o significado de uma palavra ao relacioná-la ao frame que lhe serve de pano de fundo.

As investigações acerca da unidade lexical risk vieram a motivar a construção da base de dados lexical FrameNet (BAKER et al., 1998). Pela primeira vez, traz-se uma análise mais minuciosa e prática quanto à proposta de Fillmore, na qual se levam em conta as descrições valenciais que estruturam os frames. Esse experimento é conduzido a partir de concordâncias retiradas de um corpus de 25 milhões de palavras, compilado pela American Publishing House for the Blind. Para a análise do lexema risk e das respectivas unidades lexicais, foram extraídas 1770 sentenças ${ }^{11}$. Através desse experimento, Fillmore e Atkins evidenciam que o fato de um dicionário separar os sentidos de acordo com as paráfrases possíveis, baseados em diferenças de padrões gramaticais, não permite que o usuário verifique processos metafóricos e metonímicos relacionados a determinadas unidades lexicais (FILLMORE; ATKINS, 1992), daí a necessidade de se criar um recurso organizado em torno de frames.

A Plataforma FrameNet entra em operação em 1997, consolidandose como contraparte aplicada da teoria de Fillmore e, assim, delineando minuciosamente os procedimentos metodológicos atinentes à abordagem, pautados na análise a partir de evidências empíricas fornecidas por corpora de estudo. Desse modo, conforme sintetizam Atkins, Fillmore e Johnson (2003), a FrameNet é um recurso lexicográfico computacional que descreve propriedades semânticas e sintáticas de palavras em língua inglesa, a partir de corpora eletrônicos, apresentando essa informação através de

${ }^{11}$ Os autores ressaltam que, em virtude de a metodologia ainda não estar consolidada, informaç̃es concernentes a cada uma das concordâncias foram sendo registradas a partir de uma base de dados fornecida pela Universidade de Berkeley. 
uma plataforma online. Assim, o desenvolvimento do projeto embasa-se na análise de um vasto conjunto de textos autênticos de língua inglesa, do qual são extraídas as sentenças que ilustram as unidades lexicais.

É importante destacar que a FrameNet, assim como as framenets para outras línguas, como para o hebraico (PETRUCK, 2009), o português brasileiro (SALOMÃO, 2009), o italiano (VENTURI et al., 2009) e o francês (PITEL, 2009), ainda que possam ser chamadas de léxicos computacionais, não foram desenvolvidas a partir dos preceitos da Lexicografia. O seu principal propósito é armazenar informações léxico-semânticas com base em frames em um formato que possa ser processado pelo computador. Trata-se, portanto, de bases de dados lexicais, e não dicionários propriamente ditos.

Frisa-se também que, embora tenhamos nos inspirado no projeto pioneiro FrameNet (FILLMORE et al., 2010) e nas framenets desenvolvidas posteriormente para outros idiomas, nossos projetos semânticolexicográficos, como os que resultaram no Field e no Dicionário Olímpico, guiaram-se pelo compromisso em destacar a interface com a Lexicografia Tradicional (e consequentemente a Lexicografia Eletrônica), e não propriamente com a Lexicografia Computacional. Ao invés de construirmos bases de dados lexicais, tais como as framenets, voltamo-nos para o emprego da noção de frame como princípio organizador de dicionários para uso humano.

\section{Estudos de caso}

A fim de ilustrar a aplicabilidade da Semântica de Frames, selecionamos dois trabalhos que compõem pesquisas mais amplas realizadas por integrantes do grupo de pesquisa SemanTec. São estudos bem distintos, especialmente no que diz respeito aos domínios que contemplam e à metodologia empregada, mas que compartilham do interesse em apresentar evidências para a natureza enciclopédica do significado.

\subsection{0 significado enciclopédico de "mãe"}

Moraes (2017), em dissertação intitulada "A visão enciclopédica da Semântica de Frames: uma aproximação com a Lexicografia", faz uma análise dos frames evocados pela unidade lexical mãe. A autora, tomando como referência os cinco modelos cognitivos propostos por Lakoff (1987) em sua análise da palavra mother - o modelo de nascimento, o genético, o de nutrição, o conjugal e o genealógico, assim como os frames Kinship (Parentesco) e Giving Birth (Nascimento) descritos na FrameNet, faz um estudo de corpus com o propósito de verificar a incidência de tais modelos nos dados do português.

Seguindo a mesma linha de raciocínio de Lakoff (1987, p. 75-76), que chama a atenção para a dificuldade em atribuir uma definição que contemple todos os atributos e constata que os dicionários dão conta apenas do centro prototípico desse conceito, ou seja, o sentido de mãe como a mulher que dá à luz a criança, a autora encontra alguns resultados interessantes. $O$ estudo de corpus confirmou a presença dos cinco modelos, mas revelou, também, um sentido não tradicional para o frame Relação Conjugal, haja vista os casos que ilustram modelos de família não constituídos por pai (homem), mãe (mulher) e filhos, tais como a união de duas pessoas do mesmo gênero, mãe de produção independente ou que contou com a ajuda de inseminação artificial, além de famílias compostas por pai e madrasta ou padrasto e mãe.

Em complementação ao estudo de corpus, que além do mapeamento dos frames, gerou uma lista de unidades lexicais evocadoras de tais frames, o trabalho também procurou verificar a presença dos traços dos frames nos verbetes de "mãe" em seis dicionários de língua 
geral $^{12}$. A análise lexicográfica revelou uma predominância em definir "mãe" pela visão clássica, como aponta Lakoff (1987), sendo o traço do frame Nascimento como o mais saliente. As definições do item lexical "mãe" apresentadas pelos dicionários selecionados comprovam a limitação de algumas das definições no que se refere ao conteúdo semântico: a maioria apresenta apenas o traço de "mãe" como "mulher que dá à luz" e exclui traços atrelados a informações enciclopédicas. Nesse sentido, entender o significado de "mãe", sob a ótica da Semântica de Frames, implica agregar todas essas conceptualizações e agrupar as unidades lexicais em torno da mesma estrutura de conhecimento.

\subsection{As conceptualizações do atleta paraolímpico}

O segundo trabalho a ser apresentado está vinculado à criação do Dicionário Paraolímpico ${ }^{13}$, projeto mais amplo e em desenvolvimento pelo grupo de pesquisa SemanTec. Oliveira (2019), em sua dissertação intitulada "O atleta com deficiência no contexto paraolímpico: uma análise dos frames que entram em jogo", partindo do pressuposto de que a compreensão do frame paraolímpico apresenta uma estrutura mais ampla e mais complexa de conceitos e modelos de conhecimento, faz uma investigação acerca da rede de conceptualizações que compõem o frame atleta paraolímpico. Estudos preliminares já indicavam que explorar o contexto paraolímpico implicaria lidar com o entrelaçamento de conceitos como deficiência, acessibilidade, reabilitação, direitos, preconceito, assim como políticas linguísticas.

É nesse sentido que a Semântica de Frames, ao defender que o entendimento de palavras se relaciona a estruturas cognitivas mais amplas

${ }^{12}$ Dicionário Aurélio, Dicionário Houaiss, Dicionário Michaelis, Novo Dicionário da Língua Portuguesa e Grande Dicionário da Língua Portuguesa.

fomes frames semacos. Projeto de pesquisa apresentado ao CNPq, 2018, ao Edital Bolsista de Produtividade 2018.
- os frames - se torna pertinente para compreender essas diferentes conceptualizações. Segundo tal perspectiva, uma expressão como "pessoa com deficiência" evocaria um frame distinto do evocado por expressões como "pessoa portadora de deficiência", "pessoa com necessidades especiais" ou "deficiente". Enquanto a primeira remeteria a uma estrutura de conhecimento que valoriza o componente "pessoa" e deixa a deficiência em segundo plano, as demais valorizariam o componente "deficiência". No caso do domínio em questão, portanto, além da imbricada rede de conceitos, provindos de distintos modelos de deficiência, tais como o modelo médico, o social, o jurídico e o caritativo, assim como o esportivo, há também implicações concernentes às escolhas lexicais e às próprias políticas linguísticas propostas pelos movimentos sociais de pessoas com deficiência, os quais desencorajam o emprego de palavras e expressões associadas a determinadas visões consideradas preconceituosas ou discriminatórias, tais como "cadeirante" e "aleijado".

No que se refere ao propósito de mapear as conceptualizações, Oliveira (2019) reconhece, por meio de metodologia baseada em corpus, haver uma incongruência entre as noções de pessoa com deficiência dentro e fora do contexto paraolímpico. Os dados extraídos dos textos que versam sobre a pessoa com deficiência, revelaram a perspectiva dos problemas e dificuldades enfrentados pelas pessoas com deficiência, enquanto os extraídos dos textos sobre o contexto paraolímpico, destacaram a perspectiva do atleta de alto rendimento como exemplo de superação e motivo de inspiração.

O estudo das unidades lexicais, por sua vez, evidenciou uma alta incidência de palavras relacionadas a frames que indicam uma visão negativa ou imprecisa de deficiência, como é o caso dos frames Modelo_caritativo e Modelo_social, ou com enfoque na própria deficiência, como o frame Deficiência. Incluem-se nesse caso unidades como "atleta amputado", "atleta cego", "pessoa com limitações físicas", "pessoa com necessidades especiais". 


\section{Considerações finais}

Este trabalho, discorrendo sobre a natureza enciclopédica dos frames semânticos, comprometeu-se com dois vieses: um teórico e um aplicado. No âmbito teórico, preocupamo-nos em situar, no cenário da linguística contemporânea, a Linguística Cognitiva, de modo a melhor compreender os compromissos da Semântica de Frames com tal visão de significado.

A contraparte aplicada, por sua vez, pode ser duplamente justificada. Primeiramente por ilustrar a própria evolução da teoria, que, em sua versão vigente, mostra-se comprometida com a construção de léxicos computacionais. Em segundo lugar, por explicitar o próprio contexto de pesquisa dos estudos aqui referidos, que é a interface com a Lexicografia, mais especificamente a Lexicografia Eletrônica.

Nosso foco foi restrito, à medida em que tratou especificamente da pertinência da noção de frame semântico para a prática lexicográfica. Não apenas a Semântica de Frames, mas a Semântica Cognitiva, em um sentido amplo, tem muito a oferecer para a prática lexicográfica. Categorização, polissemia, categorias radiais, protótipos e metáforas conceptuais são apenas alguns dos tantos temas que podem ser aplicados à prática lexicográfica.

\section{Referências}

ATKINS, Beryl. T. Sue; RUNDELL, Michael. The Oxford Guide to Practical Lexicography. Oxford: Oxford University Press, 2008.

BAKER, Collin; FILLMORE, Charles; LOWE, John. The Berkeley FrameNet Project. In: COLINGACL '98: Proceedings of the Conference, Association for Computational Linguistics, Montreal, 1998. https://doi.org/10.3115/980845.980860

CIENKI, Alan. Frames, Idealized Cognitive Models, and Domains. In: GEERAERTS, Dirk; CUYCKENS, Humbert (orgs.) The Oxford Handbook of Cognitive Linguistics. New York: Oxford University Press. 2017, p. 48-81.
CHISHMAN, Rove. Field: Dicionário de Expressões do Futebol - 1. ed. São Leopoldo: Plural Web, 2014

CHISHMAN, Rove. Dicionário Olímpico. Porto Alegre: Plural Web, 2016.

CHISHMAN, Rove. Convergências entre Semântica de Frames e Lexicografia Linguagem em (Dis)curso (Online). v. 16, p. 547-559, 2016. https://doi.org/ 10.1590/1982-4017-160302-0316d

CHISHMAN, Rove. A natureza enciclopédica dos frames semânticos. Projeto de pesquisa apresentado ao CNPq, 2018.

CHISHMAN, Rove et al. Field - Dicionário de Expressões do Futebol: um recurso lexicográfico baseado no aporte teórico-metodológico da Semântica de Frames. Signo Santa Cruz do Sul, v. 39, n. 67, p. 25-35, 2014. Disponível em: https://online.unisc.br/ seer/index.php/signo/article/view/5128/3819. Acesso em: 09 out. 2017. https://doi. org/10.17058/signo.v39i67.5128

CHISHMAN, Rove et al. The relevance of the Sketch Engine software to build Field Football Expressions Dictionary. RELIN, Belo Horizonte, v. 23, Edição Especial, p. 769-796, 2015. Disponível em: http://www.periodicos.letras.ufmg.br/index.php/ relin/article/view/8918/8796. Acesso em: 09 out. 2017. https://doi.org/10.17851/ 2237-2083.23.3.769-796

CHISHMAN, Rove; BRANGEL, Larissa; SPADER, Diego; DOS SANTOS, Aline Nardes : DA SILVA, Bruna. Dicionário Olímpico: a semântica de frames encontra a lexicografia eletrônica In: Linguística de Corpus: perspectivas. Porto Alegre: Instituto de Letras da UFRGS, 2018. v. 1, p. 265-298.

CROFT, William; CRUSE, Alan. Cognitive Linguistics. Cambridge: Cambridge University Press, 2004. https://doi.org/10.1017/CB09780511803864

EVANS, Vyvyan ; GREEN, Melanie. Cognitive linguistics: an introduction. Edinburgh University Press, 2006.

FAUCONNIER, Gilles. Mental Spaces. Cambridge, Mass.: The MIT Press., 1985.

FILLMORE, Charles. Scenes-and-frames semantics. In: A. Zampolli (ed.). Linguistic Structures Processing. Amsterdam: North Holland, 1977. 
FILLMORE, Charles. Frame semantics. In: The Linguistic Society of Korea (Eds.). Linguistics in the Morning Calm. Seoul: Hanshin, 1982.

FILLMORE, Charles. Frames and the semantics of understanding. In: Quaderni di Semantica, v. 6, n. 2, p. 222-254, 1985.

FILLMORE, Charles; BAKER, Collin. A frames approach to semantic analysis. In: HEINE, B.; NARROG, H. (Ed.). The Oxford Handbook of Linguistic Analysis. New York: Oxford University Press, 2010. p. 313-339.

FRAMENET. FrameNet data. Berkeley, [2018]. Disponível em: https://framenet.icsi. berkeley.edu/fndrupal/. Acesso em: 15 fev. 2019.

GEERAERTS, Dirk. Decontextualising and recontextualising tendencies in 20th century Linguistics and Literary Theory. In: Ewald Mengel, Hans-Joerg Schmid \& Michael Steppat (eds.). Anglistentag 2002 Bayreuth 369-379. Trier: Wissenschaftlicher Verlag, 2003.

LAKOFF, George. Women, fire, and dangerous things: What categories reveal about the mind. Chicago: Chicago University Press, 1987. https://doi.org/10.7208/chicago/ 9780226471013.001 .0001

LAKOFF, George; JOHNSON, Michel. Philosophy in the Flesh. New York: Basic Books, 1999.

LANGACKER, Ronald W. Foundations of Cognitive Grammar, Vol. 1: Theoretical Prerequisites. Stanford: Stanford University Press, 1987.

LEW, Robert. Linguistic semantics and lexicography: A troubled relationship. In: Małgorzata Fabiszak (ed.). Language and Meaning: Cognitive and Functional Perspectives. P. Lang, 2007. p. 217-224.

MORAIS, Ana Carla Assmann. A visão enciclopédica da Semântica de Frames: uma aproximação com a Lexicografia. Dissertação (Mestrado em Linguística Aplicada) Programa de Pós-Graduação em Linguística Aplicada. Universidade do Vale do Rio dos Sinos (UNISINOS), 2017.
OLIVEIRA, Sandra de. O atleta com deficiência no contexto paraolímpico: uma análise dos frames que entram em jogo. Dissertação (Mestrado em Linguística Aplicada) Programa de Pós-Graduação em Linguística Aplicada. Universidade do Vale do Rio dos Sinos (UNISINOS), 2019.

OSTERMANN, Carolin. Cognitive lexicography: a new approach to lexicography making use of semantic cognitive. Berlim: De Gruyter, 2016. https://doi. $\operatorname{org} / 10.1515 / 9783110424164$

PETRUCK, Miriam. Typological considerations in constructing a Hebrew FrameNet. In: BOAS, Hans (Ed.). Multilingual FrameNets in computational lexicography: Methods and applications. Berlin/New York: Mouton de Gruyter, 2009. p. 163-182.

PITEL, George. Cross-lingual labeling of semantic predicates and roles: A low-resource method based on bilingual L(atent) S(emantic) A(nalysis). In: BOAS, Hans (Ed.). Multilingual FrameNets in computational lexicography: Methods and applications. Berlin/New York: Mouton de Gruyter, 2009. p. 245-284.

ROSCH, Eleanor. Recuperando os conceitos. Tradução de Dalby Dienstbach. In: SIQUEIRA, Maity.; OLIVEIRA, Ana Flávia (Orgs.). Cadernos de Tradução, n. 31, 2012.

SALOMÃO, M. M.M. FrameNet Brasil: um trabalho em progresso. Calidoscópio, v. 7, n. 3, p. 171-182, 2009. https://doi.org/10.4013/cld.2009.73.01

SILVA, Augusto Soares da. Significado, conceptualização e experiência: sobre a natureza do significado linguístico. In: Revista Portuguesa de Humanidades 10, Faculdade de Filosofia da UCP. 2006.

SPADER, Diego. Entre conceitos e conce(p)tos: uma proposta teórico-metodológica na interface entre a onomasiologia, Lexicografia e Linguística Cognitiva. Tese (Doutorado em Linguística Aplicada). Programa de Pós-Graduação em Linguística Aplicada. Universidade do Vale do Rio dos Sinos (UNISINOS), 2019.

ZIEM, Alexander. Frames of understanding in text and discourse. Amsterdam: John Benjamins, 2014. https://doi.org/10.1075/hcp.48 